\title{
Buscando al enemigo inglés. Expediciones de guardacostas españoles al golfo del Darién, 1767-1768\%/
}

\author{
Looking for the English Enemy. Spanish Coastguards \\ Expeditions to the Gulf of Darien, 1767-1768
}

\author{
Manuel Gámez Casado \\ ORCID iD: http://orcid.org/0000-0002-5539-1104 \\ Universidad de Sevilla
}

\begin{abstract}
El presente artículo tiene como finalidad analizar las rivalidades existentes entre España e Inglaterra por el control del Darién desde el siglo XVI hasta fines del XVIII. Examinada la realidad de la zona, se pondrá especial atención a las expediciones de guardacostas españoles, aportando un estudio inédito sobre las realizadas en los años 1767 y 1768. En ellas, no solo se intentó localizar los pueblos nativos de la región, sino también posibles asentamientos ingleses que comerciasen con los indios, lo que impedía el dominio español del territorio.

Palabras Clave: Conflictos globales; Inglaterra; Darién; Nueva Granada; Caribe; Cunas; Guardacostas; Ingenieros Militares; Contrabando; Siglo XVIII.

This article aims to analyze existing rivalries between Spain and England for control of Darien since the sixteenth century until the late eighteenth. Examined the reality of the area, special attention will be paid to shipments of Spanish coastguards in the region, providing an unprecedented study on those made in the years 1767 and 1768. In them, it is not only targeted to spot the native township of the region but also the English settlements that tried to trade with the natives, which impeded the total control of the Spanish over the commerce.
\end{abstract}

KeYwords: Global Conflicts; England; Darien; New Granada; Caribbean; Cunas; Coastguard; Military Engineers; Smuggling; Eighteen Century.

Copyright: (C) 2018 CSIC. Este es un artículo de acceso abierto distribuido bajo los términos de la licencia de uso y distribución Creative Commons Reconocimiento 4.0 Internacional (CC BY 4.0).

* El presente trabajo se inscribe en el desarrollo del proyecto I+D «Ingenieros militares en el Caribe y el Golfo de México durante el siglo XVIII. Diálogo cultural, circulación transnacional y conflictos globales» HAR2015-63805-P. Ministerio de Economía y Competitividad. Gobierno de España. 


\section{Introducción}

El golfo del Darién, actual frontera entre Colombia y Panamá, fue considerado históricamente un enclave estratégico para la comunicación entre los puertos de Cartagena de Indias y Portobelo. ${ }^{1}$ Para garantizar la seguridad de la ruta se trazó un plan defensivo no solo contra las poblaciones locales, hostiles a la hegemonía española, sino también contra los enemigos europeos, ávidos por explotar la zona. De hecho, fueron continuos los enfrentamientos entre España y las potencias europeas que buscaban ampliar su presencia americana, al ser esta una región que permitía el pasaje interoceánico y cuya posesión suponía el control comercial y estratégico del Nuevo Mundo. ${ }^{2}$ Esta dificultosa pero privilegiada localización convirtió dicho territorio en centro de complejas operaciones políticas, militares y culturales, tanto en época moderna como en décadas más recientes. Dentro de estas estrategias y aprovechando la incapacidad mostrada por la Corona española de abastecer los mercados americanos, desde el siglo XVI surgió un comercio ilegal entre los nativos y las grandes potencias europeas, fundamentalmente ingleses, quienes vieron en este negocio un medio eficaz para la evasión de sus mercancías. ${ }^{3}$ Asimismo, la falta de control en el aumento poblacional por parte de las autoridades españolas provocó un exagerado incremento del consumo, necesitándose de nuevos vendedores que abasteciesen tal condición.

Todo ello alimentó el auge del contrabando en las aguas caribeñas, lo que implicó la creación de nuevas medidas de defensa para hacer frente a un negocio ilícito que debilitaba paulatinamente las arcas hispanas. En consecuencia, esto reducía el control político y territorial del Darién de las autoridades virreinales, necesitando de mecanismos que asegurasen su control. De todos los preceptos adoptados para solucionar dicho problema, entre los que se encontraban diversos proyectos de fortificaciones, destacó la creación de un cuerpo de guardacostas reales que patrullase las principales zonas de conflictos. ${ }^{4} \mathrm{Si}$ bien la historiografía ha tratado en diversas ocasiones la problemática surgida desde la fundación de la mencionada unidad, ahora se aportan nuevas noticias acerca de las misiones realizadas por tales

1 Un estudio general sobre la historia política, social y económica del Darién es el realizado por García Casares, 2008.

2 Castillero, 1995a.

3 Feliciano, 1990, 9-11.

4 Al contrabando de mercancías entre ingleses y nativos en aguas caribeñas se refieren: Gómez Molleda, 1950; Robles y Tau, 1980; Feliciano, 1989; Ojeda, 2007. 
profesionales en el golfo darienita, a partir de unos expedientes localizados que ejemplifican la relación existente entre el ejército español y los contrabandistas nativos e ingleses. Además, para el correcto entendimiento de dicha documentación es necesario contextualizar la compleja situación política y social vivida en el istmo. Para ello, aunque la bibliografía sobre el tema no sea numerosa, se atenderá a los principales estudios que aporten datos sobre el enfrentamiento entre ambos reinos en aguas caribeñas. De entre todos se prestará atención a los textos escritos por viajeros ingleses, examinando los posibles paralelismos existentes entre las misiones españolas y británicas. Igualmente, se comparará la relevancia de los guardacostas con otras ramas del ejército español presentes en el golfo, caso de los ingenieros militares, comprobándose la concordancia entre sus informes y estrategias de defensa. En suma, el uso de una metodología que aúne disciplinas como la antropología, la historia o la sociología, permitirá incrementar el conocimiento sobre la realidad darienita a fines del siglo XVIII desde diversos prismas, lo que confirma una de las principales vías de investigación de la historiografía contemporánea.

\section{Entre Balboa y Wafer: Disputas por el control del Darién durante los siglos XVI y XVII}

La Corona española ansió desde los primeros años del siglo XVI establecer una vía de comunicación interoceánica. De entre todos los viajeros que intentaron tal empresa, fue Vasco Núñez de Balboa quien lo consiguió tras el sometimiento de los pueblos locales. Gracias a ello, desde las primeras décadas del quinientos se logró el control del «paso», fijándose una ruta que uniese el Caribe con el Pacífico. ${ }^{5}$ Sin embargo, el proceso de implantación de los españoles fue lento y estuvo lleno de dificultades debido a la propia orografía del terreno y a la hostilidad de indios como los cuevas, el principal pueblo de cuantos habitaban la zona. ${ }^{6}$ A pesar de estos inconvenientes, a los españoles les valió unos pocos años para atravesar el istmo, lo que supuso una catástrofe demográfica que disminuyó la población a 15.000 nativos. Debilitados los cuevas, el belicoso pueblo de

5 Castillero, 2013.

6 No fue hasta el gobierno de Pedrarias Dávila, quien en torno a 1530 descubrió la región de Chucunaque, la más cercana al Pacífico, cuando se estableció la ruta más corta para cruzar el istmo. Véase Mena, 1992. 
los cunas aprovechó para ocupar el golfo, pues según cuentan las crónicas españolas de principios del siglo XVII, lo hicieron con contundencia. ${ }^{7}$ Los cunas protagonizaron las principales luchas contra los españoles desde los inicios de la conquista, suponiendo una amenaza para el control social de una zona estratégica.

Por otro lado, numerosas son las teorías que intentan explicar el origen de esta tribu, pues autores como Howe la han relacionado con los primitivos cuevas, mientras que otros lo hacen con distintas poblaciones del Pacifico que emigraron hacia el Caribe o con pueblos originarios de Mesoamérica. ${ }^{8}$ De entre todas las hipótesis, destaca la sugerida por Romoli, pues sospecha que los cunas llegaron hasta el río Sinú al ser empujados por la tribu de los emberás desde el alto Atrato tras la conquista. ${ }^{9}$ Ciertamente, antes de la presencia española se había producido una división entre ambos pueblos, acentuada ante la presión ejercida por los conquistadores en un intento de control del territorio darienita. Esta lucha interna finalizó con la inmigración de los cunas hacia la costa atlántica, estableciéndose entre la punta de San Blas y la desembocadura del Sinú, donde se documentan desde principios del seiscientos. ${ }^{10}$ Durante estas décadas, son frecuentes las crónicas que destacan el alto grado de albinismo entre la población cuna, lo que según Martínez Mauri es producto de un proceso de etnogénesis. ${ }^{11}$ Esta explicación contradice a otras que consideran a los cunas como endogámicos, a pesar de que el albinismo pueda darse en poblaciones exogámicas al constituirse una alteración genética en el naciente. ${ }^{12}$ Esta característica genética los convertía en una tribu singular y reconocible en la infinidad de altercados que mantuvieron con los españoles por defender el Darién. A esta particularidad se sumaban las narices chatas y la ligereza de sus cuerpos, lo que según las crónicas les permitía correr y nadar a gran velocidad. Asimismo, los viajeros describieron que sus principales armas eran saetas, lanzas y arcos de madera, al desconocer la manufactura del metal. Habituados al uso de las mismas, los cunas se caracterizaron por su crueldad durante las batallas, pues los relatos apuntan que solo perdonaban la vida del enemigo para someterlo a cruentas torturas. De entre estas costumbres, a los españoles les asombraron tanto los envenenamientos de los fetos

7 Castillero, 1995b, 30-94.

8 Howe, 1978.

9 Romoli, 1987, 50.

10 Vargas, 1993, 41-127.

11 Martínez Mauri, 2011, 35.

12 Así lo hizo Stier, 1979, 73. 
por sus madres en venganza de ciertas conductas de sus maridos, como algunos rituales funerarios en los que se bailaba en torno al fallecido. ${ }^{13}$ Estas prácticas eran insólitas para los españoles, considerando a los cunas como bárbaros y asumiendo la responsabilidad de educarlos según los convencionalismos europeos en el marco de la conquista americana.

Estos episodios continuaron durante el siglo XVII, centuria en la que franciscanos, agustinos, capuchinos, jesuitas y dominicos realizaron misiones de evangelización apoyadas por mediadores como Julián Carrisoli de Alfaraz, un joven español que había convivido desde su infancia con los cunas. ${ }^{14}$ Carrisoli actuó como intermediario entre ambas partes, alcanzando treguas de no agresión que facilitaban la labor de los religiosos en el Darién. Tan importante actuación le convirtió en alcalde y capitán militar de la provincia, erigiéndose como la principal autoridad de la Corona en el territorio más complejo de cuantos poseía en América. ${ }^{15}$ Este nombramiento facilitó al obispo Lucas Fernández la fundación, en torno a 1650, de nuevas ciudades dentro de las misiones religiosas, pretendiendo cristianizar a la población local residente en ellas. ${ }^{16}$ Con estas medidas se buscaba la creación de un mecanismo institucional que permitiese el control de los dominios americanos. ${ }^{17}$ No obstante, la hegemonía hispana no terminó de consolidarse debido a los frecuentes levantamientos organizados por los cunas, animados por el apoyo económico y militar de las potencias europeas enemigas de la Corona española. ${ }^{18}$ Estas hostilidades desembocaron en un abandono por parte de los hispanos del río Atrato, relegándose su presencia a ciudades fortificadas como Santa $\mathrm{Fe}$ de Antioquia. La fundación de estos enclaves alteraba el orden social, geográfico y político conocido hasta entonces por los cunas, lo que desembocó en nuevos intereses para los jefes tribales generados por el contacto con otras civilizaciones. Del mismo modo, los europeos se enfrentaban a un territorio desconocido, habitado por una tribu beligerante y en un medio hostil, lo que modificaba los mecanismos bélicos utilizados hasta entonces en otros contextos. De este modo, es

13 Fernández de Navarrete, 1829, 203-223.

14 Sobre las misiones religiosas llevadas a cabo en el Darién, consúltese Santa Teresa, 1956.

15 Gallup-Díaz, 2002, 18.

16 Castillero, 1995b, 225-232.

17 Dentro de las instituciones que se engloban en la estrategia política creada por España para el control del Darién en época moderna, podemos destacar el régimen de ferias y galeones, que regía el comercio y frenaba el contrabando, la creación de las audiencias, tanto la de Panamá como la de Santa Fe, y la construcción de fuertes y murallas que aseguraban la defensa de lo ya controlado. Castillero, 2004.

18 Luengo, 1961, 342. 
evidente que ante la enemistad manifestada por ambos bandos y en paralelo a las luchas por el territorio, se produjo una interacción cultural. Según Gallup-Díaz, la interrelación entre el europeo y el indio en un área marginal del reino causaba afectos mutuos, transformaba ideas impuestas y constituía historias mínimas que antropológicamente explican los fenómenos de mestizaje allí producidos. Además, estos contactos disminuían el poder de los magos, considerados como líderes, al no ser capaces de mediar con los españoles. Por ello empezaron a surgir jefes que debían cumplir con tales cometidos, apareciendo una nueva estructura organizativa entre los nativos, originada a partir de la presencia española. ${ }^{19}$

Del mismo modo, esta modernización de la organización tribal se reforzó a partir de los contactos entre los indios cunas darienitas y los ingleses, buscando estos últimos una alianza favorable para poder cruzar hacia el Pacífico por el istmo y obtener una nueva vía de contrabando. Desde este momento, el Darién y su caudaloso río Atrato fueron frecuentados por piratas británicos, quienes fueron acogidos amistosamente por la población autóctona. ${ }^{20}$ Ejemplo de estas relaciones fue la expedición capitaneada por el bucanero inglés Lionel Wafer, quien en junio de 1679 partió desde Jamaica hasta alcanzar el istmo. En la descripción de su viaje durante cuatro meses por la zona, relata que algunos indios del río Congo le hablaban en español para comunicarse, aunque rechazasen la ocupación de su territorio por los conquistadores hispanos. Además, al obtener la confianza del poblado, sus integrantes le mostraron una actitud amistosa, contraria a la mostrada ante los viajeros españoles que habitaban en el golfo. Junto a estos acercamientos, Wafer narró el encuentro mantenido con el cuna Lacenta, considerado como el principal líder de la población meridional darienita. Este aparece representado como el jefe de la tribu en el conjunto de grabados que acompaña al escrito original, testimoniando gráficamente lo descrito (figura 1). Durante su estancia, Lacenta recompensó al pirata británico con diversos honores tras curar a su mujer de una enfermedad, usando técnicas medicinales occidentales y desconocidas por los nativos. A través de este acto, Wafer se integró en el poblado hasta hablar el idioma local, comportarse según sus costumbres y vestir como ellos. Incluso algunos cunas le besaban la mano, lo respetaban como a un dirigente y le pedían el bautizo, confesándole que habían sido antiguos esclavos españoles. Todo ello denota una integración de los ingleses en las poblaciones nativas, obteniendo un beneficio

19 Gallup-Díaz, 2002, 5-6.

20 Céspedes, 1952, 240. 
estratégico y territorial en detrimento del dominio español en el Darién. ${ }^{21}$ Por este motivo, los piratas británicos conocieron todo el territorio, pasos de selvas y ríos mejor que los propios españoles, ofreciendo noticias sobre la vulnerabilidad hispana en la zona ante un futuro plan de ataque.

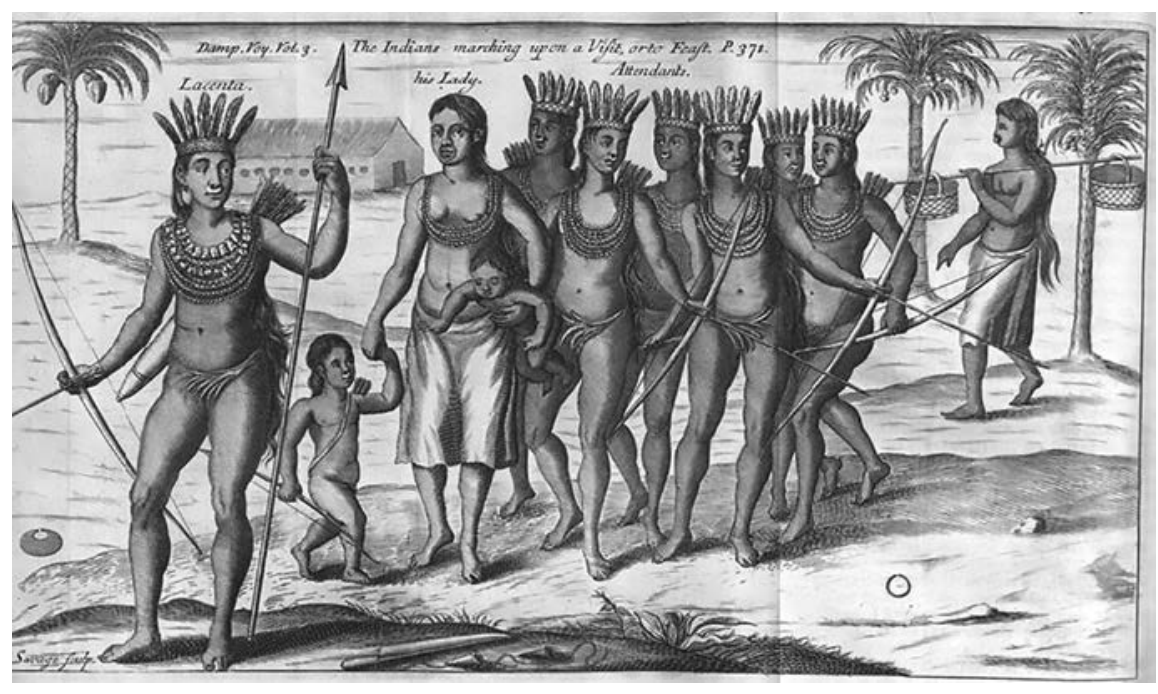

FIgURA 1. Tribu liderada por el indio Lacenta. Los viajes de Lionel Wafer al istmo del Darién. Grabado. 1705.

\section{La solución final: El Darién durante el siglo XVIII}

La situación descrita se consolidó a lo largo del siglo XVIII, pues la falta de caudales en la Hacienda española tras la guerra de Sucesión no permitía modernizar las defensas de las plazas americanas. Por el contrario, la pertenencia a la monarquía hispana de la mayor parte de los territorios del Caribe sur, suponía a priori un control de los productos y del comercio regional. No obstante, la incapacidad de la Corona española para lograr nuevos mercados donde venderlos, a diferencia del imperio inglés, provocó el bloqueo de sus arcas. Esta compleja situación fue aprovechada por los británicos para asentarse definitivamente en el Caribe.

21 Wafer, [1705] 1990, 20-30. 
Por ello, en 1713 los filibusteros ingleses lograron apoderarse de la isla Cozumel y establecer en ella una fuerte guarida, constituyendo una base para posibles ataques al imperio español en colaboración con los indios locales. ${ }^{22}$ Presentes en el Caribe, los británicos no tardaron en incrementar sus expediciones hacia el Darién, apoyando a líderes que organizaban ataques a los españoles. Sin embargo, estos continuaban centrando sus esfuerzos en misiones religiosas a cargo de jesuitas, cuyo pobre resultado era consecuencia de la anticuada estrategia exterior hispana. ${ }^{23}$ De hecho, tras la firma del tratado de paz entre España y los cunas en 1738, se había estipulado que solo los misioneros tenían potestad para internarse entre las poblaciones. En consecuencia, se promulgó una real orden en la que se requería al padre general, Francisco Retz, que enviase a varios religiosos a la zona con el fin de establecer contactos con los indios. De entre los enviados destacó el padre Carlos Brentan, quien tras haber convivido con las tribus del río Amazona, visitó personalmente a los cunas junto al padre Claudio Escobar. Los jesuitas intentaban acercarse a las poblaciones nativas en representación del poder virreinal, lo que permite comprobar la ausencia de una diplomacia española que alcanzase acuerdos contundentes para solucionar el conflicto. Ciertamente, los religiosos preponderaban la evangelización de los cunas como medio para pacificarlos. Este mecanismo se inserta dentro del proceso de adaptación de las costumbres nativas a las requeridas por las autoridades virreinales, en lo que Gallup-Díaz ha llamado la «tribalización» española del Darién. ${ }^{24}$

Dicho lo anterior, la pacificación de los grupos nativos era un requisito esencial para favorecer el comercio interoceánico, pues los cunas contrabandeaban con productos ingleses a cambio de armas y ropa a lo largo de todo el golfo de Urabá y los ríos Sinú y San Juan. No obstante, no fue hasta la llegada al trono de Carlos III cuando se dispuso por las reales órdenes del 1 y 6 de febrero de 1760 que las incursiones al Darién fueran continuas y pacíficas. Se buscaba suavizar las tensiones existentes entre todas las partes mediante el sometimiento de los indios a la monarquía hispana, aceptando el control político establecido en la mayor parte del continente. ${ }^{25}$ Asimismo, se quería alcanzar una paz hasta ahora inexistente, pues algunos levantamientos producidos por los indios y apoyados por los ingleses en las

22 Astigarraga, 2013.

23 Alcedo, 1787, 6.

24 Gallup-Díaz, 2002, 9-16.

25 Vásquez, 2012, 90. 
primeras décadas de la centuria, habían supuesto un decaimiento de las defensas españolas en el Darién. ${ }^{26}$ Ello fue aprovechado por los británicos con fines bélicos y conquistadores. Para los indios el inglés no era el pirata que destruía puertos o ciudades, sino el aliado que protegía a las poblaciones dominadas por un enemigo común. De hecho, como se ha ejemplificado con el caso de Wafer, se integraban entre las poblaciones nativas con un trato amable, actuación que en muchos casos fue tomada como modelo por los españoles que perseguían la pacificación de la región. ${ }^{27}$

Los enfrentamientos entre españoles e ingleses durante la segunda mitad del siglo XVIII, sumados a la inestabilidad surgida a partir de la guerra de la independencia de los Estados Unidos, se relacionan con las pretensiones de extensión del territorio, antecedente de las primeras ideas imperialistas consolidadas a lo largo de la siguiente centuria. Así, Inglaterra aprovechaba sus primeros avances industriales para convertirse en la potencia más ofensiva de cuantas surcaban el Caribe, utilizando tal poder para expandir su comercio y, en consecuencia, ampliar sus riquezas. Cerrados los mercados para los británicos en las colonias españolas y francesas como medida de prevención, únicamente les quedaba el contrabando como recurso mercantil. Junto a ello, la victoria de Inglaterra en la guerra de los Siete Años, considerado el primer conflicto global de la historia, les permitió no solo dominar la zona norte del continente, pues expulsaron a los franceses, sino también incrementar la influencia exterior de su política económica. ${ }^{28}$ Distintas fueron las consecuencias para España, aliada de Francia en dicho conflicto tras la firma de los Pactos de Familia, pues en 1762 Inglaterra conquistó La Habana. Ello supuso un revés para la política de Carlos III, ya que debía recuperar el control del puerto cubano e iniciar la reforma del sistema defensivo americano a través de nuevas medidas, entre las que se encontraba el incremento del número de guardacostas reales e ingenieros militares en las costas caribeñas. Destinados la mayor parte de los fondos españoles a tales cometidos, el monarca procuró consolidar la protección de los principales puertos para asegurar la red comercial. La aplicación de tales medidas requería de un examen fiscal más severo, necesitándose de un mejor control del contrabando para así evitar la pérdida de dinero. ${ }^{29}$

26 Entre esas revueltas cabe citar la perpetrada por los cunas de Tule, estudiada por GallupDíaz, 2001.

27 Sáenz, 1982, 120.

28 Véase Pocock, 2002.

29 Kuethe y Andrien, 2014, 244-331. 
Del mismo modo, tras la victoria inglesa, el rey Jorge III limitó el comercio marítimo colonial y aprobó en 1764 el conocido como Acta del Azúcar, esto es, un impuesto para regular el pago de la melaza. Con estas normas, Inglaterra iniciaba un precedente en la fiscalización colonial, pues modernizaba el cobro de aranceles y explotaba las materias primas americanas en favor de su capital. ${ }^{30}$ Estas circunstancias repercutieron en el contexto darienita pues, incrementado el poder territorial inglés, se reforzaron los contactos con grupos indígenas que veían en los británicos una solución contra el dominio español. Después de la victoria inglesa y tras el reconocimiento de la conquista de Jamaica en 1670, la presencia de los navíos británicos en aguas del Darién era legal. A la mencionada isla se le unieron otras posesiones caribeñas más alejadas de Tierra Firme, como Barbados, Nevis o Saint Kitts. Sin embargo, el control del puerto jamaicano les permitió controlar un enclave estratégico en el centro del Caribe, además de posibilitarles rutas de intercambio utilizadas según los intereses de cada momento, aunque tuviesen prohibido desembarcar en las tierras españolas. ${ }^{31}$ Del mismo modo, como se aprecia en el mapa adjunto, entorpecían el correcto funcionamiento de la ruta comercial hispana, pues los navíos que desde Cartagena de Indias se dirigían hacia La Habana o Veracruz eran interceptados por los piratas británicos que habitaban en Jamaica (figura 2). Así, para alcanzar el favor de los indios, los ingleses enviaban emisarios, caso del duque de Abermale, gobernador de Jamaica, quien se reunió con el rey de los Mosquitos con el fin de establecer una alianza contra la Corona española. ${ }^{32}$ Por su parte, también los indios visitaban Jamaica, pues es bien conocido que el cacique del poblado de la Calidonia, Ramón Mascana, había estado en tres ocasiones en la isla, donde recibió toda clase de regalos y presentes por parte de los británicos.

Dicha noticia fue comentada por Mascana al ingeniero español Antonio de Arévalo durante su expedición por el Darién en 1761, fruto de la aplicación por parte del virrey Messía de la Cerda de la real orden de pacificación anteriormente comentada. Ante la evidente pretensión de conquista del imperio inglés y tras la aplicación de las diversas medidas de defensa por Carlos III, la Corona envió a varios ingenieros para reforzar los principales ríos del golfo mediante fortificaciones o para establecer relaciones diplomáticas con los nativos. En este contexto, Arévalo intentó inútilmente

30 Brown, 2015, 133.

31 Christellow, 1941.

32 Feliciano, 1990, 141. 


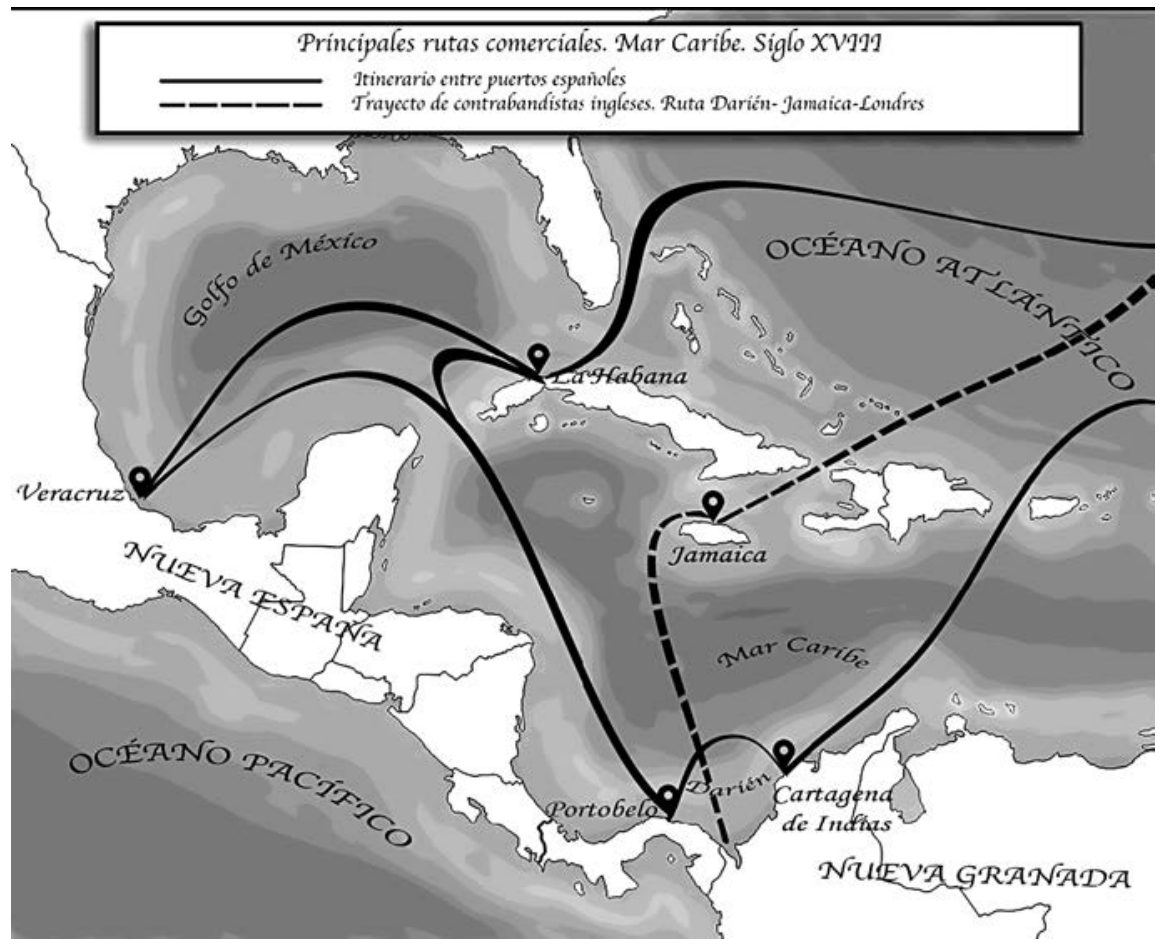

FiguRa 2. Mapa. Principales rutas comerciales españolas e inglesas. Mar Caribe. Siglo XVIII.

convencer a los indios del poder español, pero estos se mostraron reacios, enseñando con orgullo los presentes regalados por los ingleses. Esto evidencia una relación consolidada entre indios y británicos, quienes llegaron a sospechar que los españoles habían abandonado el istmo al no reconocer la población local su autoridad, lo que les permitiría establecerse allí. ${ }^{33}$ Ello explica la presencia de Arévalo y de otros ingenieros militares en el Darién a fines del siglo XVIII, pues responde a un interés por solucionar la ineficacia de los contactos establecidos previamente. Como se comprueba en la gráfica adjuntada (figura 3), durante la primera mitad del setecientos solo se ha documentado a los ingenieros Juan de Herrera y Sotomayor y Nicolás Rodríguez, realizando mapas cartográficos en los que se registraba la diversidad geográfica de la zona. ${ }^{34}$ Promulgada la real orden de 1760 durante

33 Zapatero, 1965, 59-60.

34 Véase Gámez Casado, en prensa. 
el trascurso de la guerra de los Siete Años, ascienden hasta seis los ingenieros que trabajaban en el Darién, destacando junto al referido Arévalo, otros como Juan Jiménez Donoso, Antonio de la Torre o Pedro Carbonell. Ellos no solo se ocuparon de tareas idénticas a las de sus antecesores, sino también de proyectar fortificaciones y planos hidrográficos que ayudasen al control definitivo de la región. A pesar de que estos proyectos no se ejecutasen, idéntica solución fue aplicada por los gobernantes españoles en otros puntos del Caribe sur, caso de la Guajira, en la costa este de dicho mar. En este punto, también se proyectaron diversos fuertes por los ingenieros militares, como el de Sabana del Valle, pretendiendo vigilar los importantes vínculos que la población local mantenía con el imperio inglés. ${ }^{35}$

\section{INGENIEROS MILITARES ESPAÑOLES. \\ DARIÉN. SIGLO XVIII}

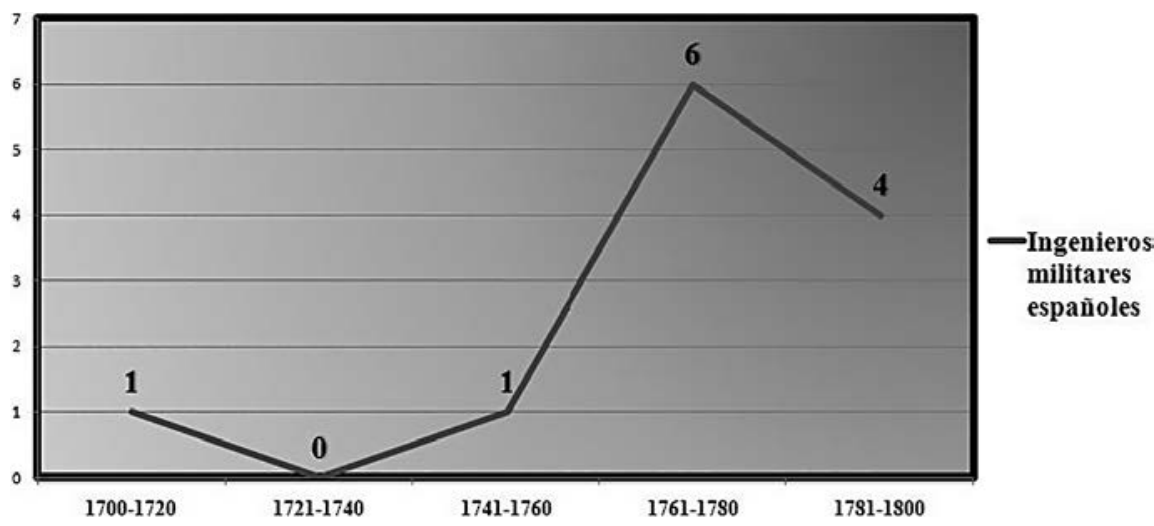

FIGURA 3. Ingenieros militares españoles en el Darién. Siglo XVIII.

\section{Los guardacostas reales. Un remedio al conflicto darienita}

El trato establecido por Arévalo con los indios darienitas fue consecuencia de la nueva estrategia de dominio establecida por el gobierno virreinal tras la promulgación de aquellas reales órdenes por Carlos III. El plan incluía no solo imponer la actividad política, social o económica española de una forma pacífica, sino también evitar la creación de asentamientos

35 Oliveros, 1970. Gámez Casado, 2016. 
ingleses ante la escasa influencia hispana en el Darién. Para ello, era necesario localizar y controlar las regiones marginales donde los británicos pudiesen actuar militarmente. Así, desde la década de 1760 se iniciaron una serie de ofensivas en busca de campamentos ingleses que pudiesen amenazar el control español en el golfo, incrementándose tras la victoria británica en la guerra de los Siete Años. Estas expediciones fueron comandadas por los guardacostas reales, encargados de combatir el contrabando caribeño y proteger a los navíos españoles que legalmente comerciaban en el sector. Las autoridades virreinales obedecieron a las medidas adoptadas por sus superiores, armando una serie de buques corsarios que defendieron el litoral y los diferentes ríos darienitas. ${ }^{36}$ Los guardacostas debían apresar a los extranjeros que encontrasen escondidos en barracas o chozas de cualquier río del golfo, pues al tener prohibido el desembarco en tierras españolas, solo podían estar ahí para contrabandear.

Dentro de estas expediciones, se encuentra la ordenada por Francisco Bances, comandante de guardacostas de Cartagena de Indias, en el golfo del Darién en 1767. La intención era destruir un almacén de ropas que al parecer tenían los ingleses en el río Gandí, al norte de la actual provincia colombiana de Chocó, prueba del asentamiento ilegal que los británicos habían establecido en el territorio. ${ }^{37}$ Como se ha dicho, los ingleses tenían permitido navegar a través de las aguas darienitas, pero se sospechaba que habían desembarcado en la orilla de alguno de los ríos que jalonan el golfo, lo que resultaba una acción ilícita y amenazante para el control hispano. Además, se querían registrar los establecimientos cunas e ingleses de los ríos para frenar las relaciones existentes entre ambas poblaciones y así consolidar la débil presencia española allí. La localización de las copias de los diarios escritos por los militares españoles que realizaron estas expediciones, enviadas a Francisco Bances, así como otra documentación relativa al caso, permite aportar nuevos datos sobre la misión, los objetivos perseguidos y el desarrollo de las mismas. Igualmente, mediante esta encomienda se contribuye con un nuevo episodio a los comentados en las líneas precedentes dentro de las soluciones para la problemática tribal, de la cual dependía la solidez del comercio español en ultramar y parte de la riqueza de todo su reino. Así, el objetivo de esta empresa y de las otras protagonizadas por

36 No obstante, el cuerpo de guardacostas no era nuevo, pues en 1521 se había creado la armada de guardacostas andaluces, encargada de resguardar a los barcos en sus viajes a las Indias. Mira, 1997.

37 Feliciano, 1990, 153. 
los guardacostas españoles, no era luchar contra los belicosos cunas, sino reducir la presencia inglesa en el Darién y por tanto frenar sus pretensiones de control territorial.

El guardacostas Francisco Bances ordenó que al frente de la primera expedición estuviesen el capitán Santiago Muñoz de Velasco y el teniente Martín Vázquez. ${ }^{38}$ Ambos recogieron en sendos diarios las noticias referentes a la misión, detallando los acontecimientos vividos y estableciendo unas conclusiones útiles para el desarrollo de la política de pacificación darienita. ${ }^{39}$ Del inicio de la expedición informó Bances al secretario de Estado, Julián de Arriaga, mediante una carta ${ }^{40}$ en la que comenta que por orden del virrey Pedro Messía de la Cerda, el gobernador de Cartagena de Indias, Fernando Morillo Velarde, había ordenado cuatro días antes armar tres piraguas y una lancha para llevar a cabo la misión. Asimismo, el virrey había permitido que, en caso de que encontrasen algún asentamiento, las tropas lo destruyeran con el fin de castigar a los indios y desalojar a los británicos allí establecidos, lo que pone en duda las ideas de pacificación atribuidas al gobierno de Carlos III.

Las copias tanto del diario del teniente Martín Vázquez, ${ }^{41}$ como la del redactado por el capitán Santiago Muñoz de Velasco, ${ }^{42}$ fueron enviadas a Bances una vez finalizada la expedición. Los escritos se inician el 22 de mayo de 1767, cuando se embarcaron en cada una de las dos balandras veinticinco hombres de la tropa de tierra, acompañados de dos oficiales. Los militares se enfrentaban a un recorrido a través del litoral darienita mediante una navegación de cabotaje. Como se puede apreciar en el plano adjunto (figura 4), con ello inspeccionarían con mayor rigurosidad los

38 El capitán Santiago Muñoz de Velasco, nacido en Santander y desde 1758 destinado en América, ya había participado en diversos enfrentamientos contra los ingleses, como el que supuso la rendición de La Habana en 1762 donde sufrió la muerte de su tío, el marino Luis Vicente de Velasco. Pezuela, 1859, 61.

39 Además de los diarios del capitán Santiago Muñoz de Velasco y del teniente Martín Vázquez, se ha hallado un tercero, escrito por el capitán de milicias Cayetano López y tras su muerte continuado por el marino Pedro Barcinet; no obstante, este es menos minucioso en sus descripciones, no aportando tantos datos como los dos anteriores. Diario de Cayetano López y Pedro Barcinet, Sevilla, 23 de mayo al 23 de junio de 1767, Archivo General de Indias (en adelante AGI), Santa Fe, 943.

40 Francisco Bances a bordo de la fragata Soledad, Cartagena de Indias, 23 de mayo de 1767, AGI, Santa Fe, 943.

41 Francisco Bances, Diario del teniente del navío don Martín Vázquez, comandante de las balandras Pacífica y Pastora. Copia del original que devolví a Martín Vázquez, Cartagena de Indias, 7 de julio de 1767, AGI, Santa Fe, 943.

42 Francisco Bances, Diario de lo acaecido desde el día 22 de mayo que nos hicimos a la vela para el golfo del Darién hasta el 29 de junio que volvimos. Es copia de su original que devolví a don Santiago Muñoz de Velasco, Cartagena de Indias, 7 de julio de 1767, AGI, Santa Fe, 943. 


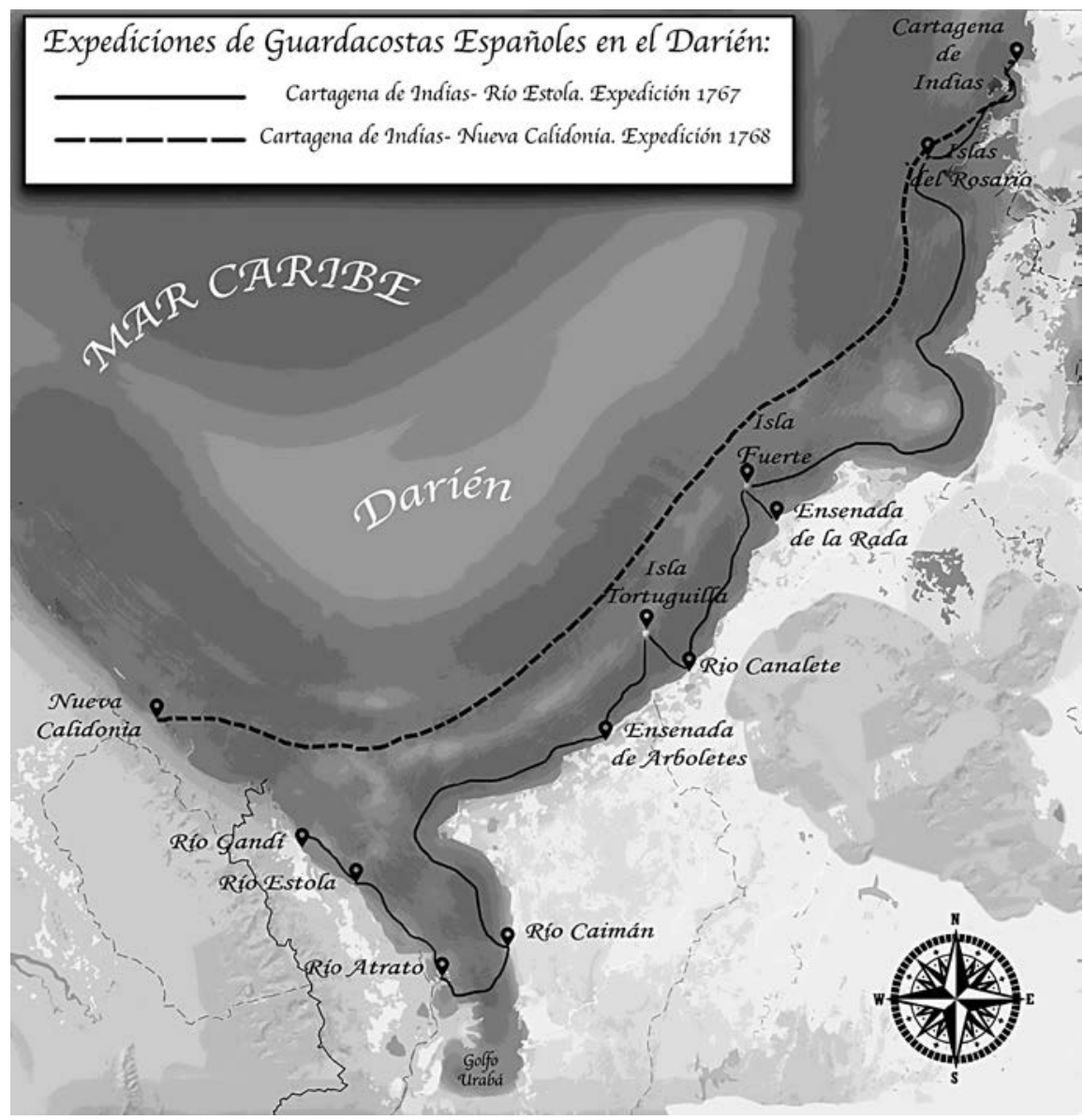

Figura 4. Mapa. Expediciones de guardacostas españoles en el Darién realizadas en 1767 y 1768.

numerosos accidentes geográficos que constituían una costa compleja, pues la sucesión de cabos y golfos ocultaba al enemigo. Tras partir de Cartagena de Indias, los barcos llegaron a la isla del Rosario dos días después a pesar de no haber demasiada distancia entre ambos puntos. Desde allí alcanzaron Isla Fuerte, donde se incorporaron las lanchas y las piraguas que transportaban el armamento. Al día siguiente, dichas embarcaciones fueron enviadas a reconocer la ensenada de la Rada y el río Canalete, para después volver 
a unirse a la expedición en la isla Tortuguilla. Se buscaba utilizar los barcos menores como avanzadilla para registrar posibles poblaciones locales y asentamientos ingleses antes de la llegada del grueso de la expedición. En contra de todo pronóstico, las embarcaciones encontraron a dos náufragos españoles en un monte cercano, perdidos tras hundirse su balandra en la Semana Santa de ese año. Uno era natural de Portobelo, mientras que el otro era un mulato de Curaçao. Ambos estaban débiles, hambrientos y asustados ante un posible ataque indígena, lo que testimonia las hostilidades de los cunas. Una vez rescatados, la expedición continuó su marcha, pero al pasar por la ensenada de los Arboletes, el náufrago mulato divisó una estructura con troneras, sospechando que fuera una posible fortificación nativa de materiales vernáculos o empalizadas construida para defender algún poblado. No obstante, el marino Pedro Barcinet, integrante de la expedición y nativo, aclaró que era un volcán de azufre que en la distancia se confundía con una construcción india. Ante la sospecha de un posible asentamiento enemigo, se fondeó en un punto cercano a la ensenada para que la tripulación reconociese el lugar. Allí, los marinos registraron toda la playa pero no encontraron otra cosa que el volcán descrito por Barcinet. Era, pues, evidente el ansia por descubrir alguna prueba de asiento inglés en la zona, para de este modo demostrar el contrabando existente y justificar un ataque a los buques y mercaderes británicos.

Fracasado el primer intento, la expedición navegó hasta la desembocadura del río Caimán, introduciéndose en el golfo de Urabá. Como se aprecia en el plano (figura 4), la estrechez de este territorio era una amenaza para los españoles, pues podían ser atacados desde diversos puntos sin posibilidad de escapar. Allí, avistaron a dos indios ondeando una bandera blanca con los que conversó Pedro Barcinet, conocedor de la lengua autóctona. Uno de los nativos se hacía llamar Bernardino, mientras que el otro era el yerno del cacique de la tribu a la que pertenecían. Ambos querían saber quiénes eran y qué querían, negándose en rotundo a que su líder fuese a bordo de los barcos españoles, ya que debía celebrar dos fiestas grandes, una de la chicha y un bautismo. A pesar de ello, los españoles querían explorar el asentamiento para obtener información sobre el terreno. Por este motivo, la expedición se internó en el río Caimán, donde encontraron una canoa con otros dos indios que hablaban castellano y que habían sido enviados por el cacique Pedro Toro. Estos advirtieron que el líder no los recibiría al encontrarse en ese momento junto a seis indios de la costa oeste, los cuales, si sospechaban de algún trato con los españoles, responderían 
con violentos ataques a su pueblo. Por ello, en nombre de su cacique pedían que no se adentrasen más en el río, ya que podría perjudicar la relación de su poblado con los vecinos. A pesar de la advertencia, Barcinet y diez marineros reconocieron las inmediaciones del río Caimán a bordo de piraguas. No obstante, no encontraron más que algunos objetos pertenecientes a la tribu, por lo que volvieron a reencontrarse con los indios. Esta vez los nativos aceptaron que los españoles estuviesen en su jurisdicción a cambio de que no destruyesen sus propiedades, lo que denota una actitud lejana a las amenazas descritas por las crónicas. Diferente era la mostrada por los españoles, quienes incumplían las advertencias de los nativos con el fin de exterminar cualquier poblado inglés.

Controlado el primer asentamiento del río Caimán, la expedición continuó su marcha hasta que el marino de la Pastora, Fernando Enrique, advirtió que algunos indios se escondían en los montes cercanos ante la presencia de las embarcaciones españolas. De inmediato, el capitán Santiago Muñoz de Velasco ordenó reconocer la playa, tomar la boca del río para atacar a los avistados y apresarlos en caso de ser indios del oeste. Examinada la playa, los españoles únicamente encontraron algunas embarcaciones abandonadas. Ante tal confusión, Muñoz de Velasco se reunió con el cacique Pedro Toro para saber si conocía los planes de armamento de los asentamientos vecinos, a lo que respondió que no. El encuentro resultó pacífico, aunque el cacique insistió en que lucharían para evitar que poblasen la zona o construyesen fortificaciones con su apoyo, ya que ello supondría un enfrentamiento de su poblado con los violentos cunas de la costa oeste del Chocó. De hecho, reconoció que estos los tenían amenazados por los continuos contactos que habían tenido con los españoles. Finalmente, el encuentro concluyó con unos tiros al aire y con la reanudación de la marcha por parte de la expedición española. Así, a diferencia de las formas amables mostradas por los ingleses, caso de Wafer, quienes intentaban colaborar con los nativos para ganarse su favor, los españoles eran distantes con los indios, pues las necesidades de control del territorio así lo exigían.

Continuando la ruta, al llegar a la desembocadura del río Atrato los militares encontraron un poblado de pescadores de carey. Sospechando que se tratase del asentamiento inglés que buscaban, el teniente Martín Vázquez dio orden a Barcinet de examinar el asentamiento. En este momento, avistaron una embarcación con bandera inglesa, la cual, tras advertir la presencia española, desplegó sus velas y huyó hacía el río Estola, situado más al norte. De inmediato, tres piraguas españolas fueron a reconocer la 
bahía, pero fracasaron en el intento de apresar el buque. En cualquier caso, las sospechas se habían confirmado al descubrir un navío inglés en la zona, el cual formaría parte de una flota que recorría los diferentes ríos en busca de poblados nativos en los que comerciar. Ello obligó al capitán Muñoz de Velasco a disponer que al amanecer se quemasen las casas de los indios del Estola. Con la salida del sol se produjo el ataque, pero ante el sonido de los fusiles los indios corrieron hacía allí en actitud agresiva, resultando heridos hasta cuatro marinos españoles.

Tras ello, algunos indios huyeron en piraguas hacia el cabo Tiburón, siendo apresados dos por los españoles. Interrogados por Barcinet, el primero dijo llamarse Pedro, vivir cerca del río Estola y no saber nada sobre los contactos con otros pueblos. En la declaración añadió que se proveían de camisas, peines, pólvora, escopetas o machetes a cambio de cacao, carey y tortugas. Ello hacía sospechar de un posible contacto con los británicos llegados desde Jamaica, quienes surtirían de los víveres y armamentos necesarios para luchar contra el dominio español. Asimismo, el nativo confesó que no hacía mucho había llegado a la zona una embarcación inglesa cuya tripulación se interesaba por entablar relaciones con los poblados, ofreciéndoles diversos presentes. En cuanto al otro indio detenido, cuyo nombre no reveló, afirmó que un inglés casado con una india de la tribu de los mosquitos intercambiaba por cacao cualquier producto proveniente de Jamaica. ${ }^{43}$ Por último, se le obligó a que acompañase a la expedición hispana en busca de los posibles asentamientos del río Gandí, donde parecía encontrarse el principal foco de los contactos entre los indios y los ingleses.

Para destruir el asentamiento era necesario no internarse demasiado en los canales afluentes, pues podrían encontrar demasiada resistencia. $\mathrm{Al}$ poco de comenzar la ruta por el Gandí, se inició el intercambio de disparos entre españoles y cunas, finalizando la batalla con varios heridos. Los indios eran muy numerosos y hábiles, lo que posibilitaba que entre ellos hubiera ingleses que los reforzarían. Sin embargo, la densa maleza no permitía identificar a cada uno de los enemigos. Además, el fuego y las flechas habían disminuido a medida que se desarrollaba la batalla, tanto que al final solo se oían tiros desperdigados, prueba de la falta de coordinación entre los combatientes al pertenecer estos a un ejército heterogéneo formado por británicos e indios. El saldo final fue de nueve muertos españoles durante

43 Francisco Bances, declaraciones tomadas a dos indios prisioneros por medio del intérprete Pedro Barcinet, a bordo de la balandra San José, La Pacífica, al ancla frente de las bocas de los ríos Estola y Gandí, 22 de junio de 1767, AGI, Santa Fe, 943. 
la contienda, otros tres fallecidos a causa de las graves heridas, y hasta cincuenta heridos, mientras que fueron cuarenta los nativos muertos. Al día siguiente se avistaron en la zona hasta siete piraguas con banderas inglesas dispuestas a atacar, siendo obligadas a arribar ante el ataque de una de las balandras españolas. Tras ello, tanto indios como ingleses huyeron hacia el monte, donde lograron camuflarse y finalmente escapar. Significativo resulta que el teniente Martín Vázquez recogiese en su diario que quienes llevaron a cabo tal ataque, tanto desde las piraguas como desde el monte, eran unos doscientos hombres y en su mayoría ingleses. De este modo se confirmaba su establecimiento en las inmediaciones del río Gandí, en donde se localizaría el almacén de ropa y, por consiguiente, el asentamiento británico. La ubicación del río beneficiaba a la estrategia británica, pues era efectivo tanto para huir hacia Jamaica como para atacar a los barcos españoles que se internasen en el golfo. Ante tal circunstancia, y ante la superioridad de los cunas, era imposible que los españoles vencieran con un número tan reducido de efectivos. Por ello, tras registrar la posición de los pueblos indios y tras descubrir el posicionamiento estratégico inglés, la expedición inició su regreso a Cartagena de Indias, donde informarían de todo lo ocurrido.

Tras conocer lo acaecido, el gobernador Fernando Morillo informó por carta al virrey que era «urgentísimo» contener a los indios e impedir que los ingleses se adueñen del territorio, como ya lo estaban haciendo. ${ }^{44}$ Instruido de forma oficial por el capitán, Morillo volvería a escribir al virrey para trazar un plan de ataque de mayor envergadura contra los asentamientos localizados, lo que permitiría un golpe de efecto contra la presencia inglesa en aguas caribeñas. Se buscaba cambiar el pensamiento pacifista de los gobernantes locales ante la hostilidad mostrada en el territorio darienita hacia los soldados españoles. Asimismo, cualquier relación diplomática se pensaba inútil, abogándose por incrementar la dureza en las futuras expediciones a la región. Sin embargo, a diferencia de lo propuesto por Arévalo en el río Caimán, no se proyectaron fortificaciones ni asentamientos españoles que pudiesen controlar la desembocadura del río Gandí, tan solo se hicieron prospecciones para registrar lo allí existente con el fin de trazar una estrategia definitiva.

Por otra parte, tanto el capitán Muñoz de Velasco como el teniente Martín Vázquez, entregaron sus respectivos diarios al comandante Francisco Bances, quien los remitió a la Corte junto a una carta en la que expresa

44 Carta de Fernando Morillo a Pedro Messía de la Cerda, Cartagena de Indias, 2 de julio de 1767, AGI, Santa Fe, 943. 
no tener dudas de la presencia inglesa en la costa del Darién, reclamando un segundo viaje hasta el puerto de Calidonia, al norte del golfo. ${ }^{45}$ En dicho territorio se sospechaba que los ingleses podían haber construido una fortificación, al haber sido un objetivo común de británicos y franceses, demostrando con ello la importancia comercial del mismo. Allí fueron detenidos en la década de 1740 algunos mercaderes galos que practicaban el contrabando, trayendo productos desde Jamaica, poniendo de manifiesto una colaboración entre ingleses, franceses e indios contra España. ${ }^{46}$ Incluso los propios escoceses habían edificado una serie de baterías a finales del siglo XVII en dicho puerto, destruidas en 1699 durante el gobierno de Juan Díaz de Pimienta. ${ }^{47}$ Ello justificaba la necesidad de dominio político, económico y social que la Corona española ansiaba en el golfo del Darién.

Desde que el antiguo gobernador darienita, Miguel Remón, afirmase en 1754 que la solución al conflicto era asegurar la costa del norte para impedir el comercio con extranjeros, la idea de defender y fortificar el puerto de Calidonia fue una constante para la Corona española. ${ }^{48}$ Por ello, ahora se pretendía confirmar si en ese punto existían asentamientos británicos como los encontrados en el río Gandí, para así anteponerse al posible ataque británico y preparar una defensa eficaz en favor de los intereses comerciales españoles. De hecho, era bien conocido que el cacique Pancho de los indios de la Calidonia, se limitaba a cumplir órdenes inglesas, sospechándose que permitiría la construcción de fuertes británicos allí, aunque estos no fuesen de gran envergadura ${ }^{49}$ Ante este condicionante, la respuesta por parte del rey se produjo el 28 de octubre, aceptando que se enviase una balandra al puerto de Calidonia para completar la búsqueda de asentamientos en el golfo. ${ }^{50}$ Como se muestra en el plano (figura 4), la distancia a recorrer era mayor que en la primera de las expediciones, por lo que se trazó una ruta directa que uniese las dos plazas. ${ }^{51}$ Así, la expedición de los guardacostas

45 Carta de Francisco Bances a Julián de Arriaga, Cartagena de Indias, 7 de julio de 1767, AGI, Santa Fe, 943.

46 Gómez González, 2008, 154-155.

47 Marco, 1951, 131. Véase Vaughan, 1966.

48 Castillero, 1995b, 324-325.

49 El ingeniero militar Antonio de Arévalo, tras contactar con el capitán Pancho, dice de él ser un fugitivo, apóstata y rebelde, amigo íntimo y apasionado de los ingleses. Zapatero, 1965, 54-57.

50 A don Francisco Bances, sobre la expedición del golfo del Darién de que ha dado cuenta, San Lorenzo, 28 de octubre de 1767, AGI, Santa Fe, 943.

51 Francisco Morillo a Julián de Arriaga, Cartagena de Indias, 21 de marzo de 1768 (El gobernador interino de Cartagena de Indias acusa el recibo de la real orden que se le comunica sobre prevenirse al virrey de Santa Fe lo que debe hacer para desalojar a los ingleses del puerto de Calidonia), AGI, Santa Fe, 943. 
se inició el 10 de julio de 1768, llegando a Calidonia quince días después. Finalizado el reconocimiento el día 26 del mismo mes, el teniente Martín Vázquez admitió que no había encontrado ni fortificaciones, ni preparativos para la construcción de algún edificio defensivo. Tras ello concluyeron las expediciones de los guardacostas ahora estudiadas, denotándose cómo no solo se adentraron en los peligrosos ríos darienitas sino también registraron nuevos poblados y describieron la evidente presencia inglesa en el territorio de mayor complejidad social, política y económica de cuantos conforman el continente americano.

\section{Conclusiones}

Acabadas las expediciones comentadas, se había logrado completar la búsqueda de asentamientos indios e ingleses en el golfo, contabilizando la población de cada uno de los pueblos y comprobando sus hostilidades ante la presencia española. La información recogida permitió que en futuras expediciones, como la realizada por el ingeniero Antonio de Arévalo en 1785, se pudiesen fundar nuevas ciudades que impusieran la autoridad de los españoles, lo que supuso un cambio de estrategia contra las políticas pacifistas promulgadas por Carlos III. Incluso en 1787 se firmó un acuerdo de paz entre ingleses, indios y españoles, representados por Arévalo, en el que se especificó que los nativos no podían tomar decisiones por cuenta propia, teniendo que obtener la autorización para comerciar de los gobernantes de Portobelo, Panamá o Cartagena de Indias. ${ }^{52}$ Sin embargo, la muerte de Arévalo supuso una desatención de la zona, incrementándose el debilitamiento de la autoridad española. Ello provocó que en 1805 el gobernador de la región, Juan Antonio de la Mata, se viese superado por una oleada de destrucción que provocaría los primeros procesos independentistas en el que fue uno de los territorios más conflictivos de cuantos pertenecieron a España en el Nuevo Mundo.

El desarrollo de las expediciones de guardacostas españoles expuesto en las líneas precedentes denota un intento de control por parte de la Corona de un espacio pretendidamente dominado, pero cuya realidad era dispar. La necesidad de establecer una soberanía sobre las poblaciones locales del Darién hizo que nunca se aprobase el proceso de españolización del golfo,

52 Rodríguez, 2014. 
favoreciendo a otras potencias europeas que, mediante la utilización de otros mecanismos, se habían ganado el respeto y la confianza de los indios. Este fue el caso del imperio inglés, que había desarrollado una importante flota naval que constituía el grueso de su ejército, fomentando una tradición marítima que permitiría dominar las aguas del Caribe, a pesar de no controlar los principales puertos de este mar. Ciertamente, tras los acuerdos alcanzados a fines del siglo XVII y durante la guerra de los Siete Años, Inglaterra no pudo establecer asientos portuarios consolidados, en cambio, el dominio de Jamaica le permitía alcanzar el litoral de Tierra Firme en pocas jornadas. Junto a ello, la tradición marítima inglesa fomentó un comercio de guerrillas, mediante el cual pudiesen intercambiar productos sin necesidad de asentarse en el territorio, lo que supondría una sobreexposición ante posibles ataques españoles. Asimismo, como declaró el indio Pedro, la falta de armas y ropa era suplida mediante la permuta con los comerciantes ingleses de otros productos como el cacao. De este modo se favorecía un contrabando que mermaba la economía hispana al chamarilear con objetos de importante valor que se escapaban de los comerciantes lícitos, denotando una falta de control en un territorio de supuesto mando español.

La disparidad existente entre las estrategias españolas y británicas en el Darién, así como el modo de someter a la población local, provocó resultados muy desiguales en las relaciones con los cunas. En efecto, los acuerdos con los comerciantes ingleses eran continuos, generando una enemistad con los españoles a los que consideraban invasores. La ocupación de sus tierras era la principal razón por la que los indios atacaban a los hispanos, pues no existía un deseo de reinar o extender su territorio, tan solo de defender sus poblados ante la imposición de una jerarquía extranjera. Se ha comprobado que los indios hablaron español con los guardacostas e incluso les permitieron estar en el río Caimán a cambio de que no destruyesen sus propiedades. Igualmente, el cacique Pedro Toro colaboró con los militares españoles en un intento de cooperación que se rompió tras contrastarse la presencia inglesa en el golfo. Esta tolerancia no era óbice para negar el gobierno español, pues los cunas se consideraban soberanos del istmo y, por tanto, solo admitían la autoridad local del líder. Incluso los indios reconocían que su actitud belicosa era producto de la venganza que los españoles merecían por las muertes de sus ascendentes..$^{53} \mathrm{El}$ establecer unas normas sociales occidentalizantes entre una población acostumbrada a vivir

53 Fernández de Navarrete, 1829, 206. 
en libertad, era una misión compleja. No obstante, resultó exitosa en otros puntos del continente, pues así ocurrió con el sometimiento de imperios prehispánicos cuya articulación política era más avanzada. Precisamente la carencia de leyes a las que obedecer desembocó en un desorden social, ya que, a pesar de la existencia de un líder, los cunas carecían de una estructura coherente. Esta desorganización se reflejaba en una falta de justicia, pues los indios no castigaban a sus malhechores ni recibían correcciones ante cualquier delito. Ello quiso ser modificado por los españoles, quienes intentaron someterlos bajo las normas impuestas por los gobiernos virreinales.

Este desconocimiento por las autoridades españolas de las costumbres y tradiciones locales se enlaza con la falta de interés mostrada por los descubridores de un área calificada como marginal. Las sucesivas epidemias y la violencia de sus pobladores repercutieron en un abandono de ciertos puntos del istmo. De la misma forma, la complejidad geográfica de la región era una dificultad añadida para la conquista pues, como se ha comprobado con los mapas que acompañan al texto, eran numerosos los ríos, fondeaderos y accidentes geográficos que jalonaban el litoral. Por tanto, centrados los esfuerzos en explotar las minas de Cana y en defender el paso interoceánico ante los ataques piráticos, los españoles no se esforzaron en adaptar su plan de colonización a un territorio que lo requería. Además, preocupados por controlar los puertos principales, caso de Portobelo, Cartagena de Indias, Veracruz o La Habana, eran escasos los recursos militares destinados al Darién, resultando incomprensible esta desidia ante la privilegiada localización del golfo. Asimismo, como ha señalado Castillero, al no constituirse una Hacienda y ante la falta de mano de obra indígena, nunca se implantaron los sistemas de mita y repartimiento, por lo que el beneficio económico obtenido por España era escaso, generando una desatención por parte de los gobernadores locales. ${ }^{54}$

En contra, sus aliados ingleses aceptaron sus libertades, toleraron sus costumbres y empatizaron con sus problemas, lo que repercutió en una relación positiva que satisfacía las apetencias comerciales británicas. De hecho, como pudo comprobar el marino Pedro Barcinet, se consumaron matrimonios entre indias y nautas británicos, probándose la absoluta integración de ambas culturas. Estas alianzas se fortalecieron al identificar a un enemigo común, pues como ocurrió durante el episodio narrado en el río Gandí, nativos e ingleses lucharon juntos contra el dominio de la Corona

54 Castillero, 1995b, 240-244. 
española. A estos últimos solo les quedaba imponer unas pautas estrictas a través de la creación de unidades militares como los guardacostas, pues combatir contra la flota inglesa resultaba inasequible. Asimismo, descartados los proyectos de fortificaciones en los principales ríos darienitas, la desventaja estratégica española en Tierra Firme era evidente. Ello hizo que desde los viajes de Cristóbal Colon hasta el siglo XIX existiese un interés por dominar el istmo a través de cualquier medio. Sin embargo, fracasados los intentos de control en el Darién durante los tres siglos de ocupación, la soberanía cuna permaneció inalterada. Todo ello permite dudar de la autoridad española en América, pues eran demasiados los pueblos que se resistían a abandonar sus creencias, su gobierno y su libertad.

Recibido el 23 de junio de 2016 Segunda versión el 19 de noviembre de 2016 Aceptado el 14 de diciembre de 2016

\section{Referencias bibliográficas}

Alcedo, Antonio, Diccionario geográfico-histórico de las Indias occidentales o América, Madrid, Imprenta de Manuel González, 1787.

Astigarraga, Jesús, «Las reflexiones de Simón de Aragorri y la reforma del comercio atlántico español», Revista de Indias, LXXIII, 259, Madrid, 2013, 759-788.

Brown, Kendall, «Guerra, impuestos y reformas financieras: las colonias españolas e inglesas del siglo XVIII», Histórica, 2, Lima, 2015, 117-150.

Castillero Calvo, Alfredo, «Las comunicaciones marítimas en el imperio transoceánico español y la conexión transístmica (siglos XVI- XVII)», en Las comunicaciones entre Europa y América. Actas I Congreso Internacional de Comunicaciones, Madrid, Ministerio de Obras Públicas, 1995a, 21-32.

Castillero Calvo, Alfredo, Conquista, evangelización y resistencia, Panamá, Editorial Mariano Arosemena, 1995b.

Castillero Calvo, Alfredo, «Transitismo y dependencia. El caso del istmo de Panamá», Anuario de Estudios Centroamericanos, 40, 1, Universidad de Costa Rica, 2004, 165-186.

Castillero Calvo, Alfredo, «Los primeros gobiernos de Tierra Firme. 1510-1565», en Núñez de Balboa, Octavio Méndez Pereira, edición conmemorativa de la Academia Panameña de la Lengua, Panamá, 2013, 45-76.

Christellow, Allan, «Contraband trade between Jamaica and the Spanish main, and the free port act of 1766», Hispanic American Historical Review, XXII, Durham, NC, 1941, 309-343. 
Feliciano Ramos, Héctor, «El auge del contrabando: su tipología y sus ámbitos», en Ramos Pérez, D. y Díaz-Trechuelo, L. (coords.), América en el siglo XVIII, vol. XI-2, La Ilustración en América, Madrid, Ed. Rialp, 1989, 357-372.

Feliciano Ramos, Héctor R., El contrabando inglés en el Caribe y el Golfo de México (1748-1778), Sevilla, Diputación Provincial, 1990.

Fernández de Navarrete, Martín (coord.), Colección de los viajes y descubrimientos que hicieron por mar los españoles desde fines del siglo XV. Tomo III. Viajes menores y los de Vespucio: Poblaciones en el Darién, Madrid, Imprenta Real, 1829.

Gallup-Díaz, Ignacio, "'Haven't We Come to Kill the Spaniards?" The Tule Upheaval in Eastern Panama, 1727-1728», Colonial Latin American Review, 10, 2001, 251-271.

Gallup-Díaz, Ignacio, The Door of the Seas and Key to the Universe: Indians Politics and Imperial Rivalry in the Darien, 1640-1750, New York, Columbia University Press, 2002.

Gámez Casado, Manuel, «La pacificación de La Guajira por el ingeniero Antonio de Arévalo. Sobre el proyecto de defensa de Sabana del Valle», Laboratorio de Arte, 28, Sevilla, 2016, 373-386.

Gámez Casado, Manuel, «Ingenieros militares españoles en Nueva Granada durante el siglo XVIII. Movilidad, proyectos y expediciones», Revista de Indias, Madrid, en prensa.

García Casares, Joaquín, Historia del Darién, Panamá, Editorial Universitaria, 2008.

Gómez González, Juan Sebastián, «Las tensiones de una frontera ístmica: alianzas, rebeliones y comercio ilícito en el Darién. Siglo XVIII», Historia y sociedad, 15, Medellín, 2008, 143-164.

Gómez Molleda, María Dolores, «El contrabando inglés en América», Hispania. Revista española de historia, 39, Madrid, 1950, 336-369.

Howe, James, «Algunos problemas no resueltos de la etnohistoria del este de Panamá», Revista Panameña de Antropología, 2, Panamá, 1978, 30-47.

Kuethe, Allan y Andrien, Kenneth, The Spanish Atlantic World in the Eighteenth Century. War and the Bourbon Reforms, 1713-1796, New York, Cambridge University Press, 2014.

Luengo Muñoz, Manuel, «Génesis de las expediciones militares al Darién en 1785-6», Anuario de Estudios Americanos, XVIII, Sevilla, 1961, 335-416.

Martínez Mauri, Mónica, La autonomía indígena en Panamá: la experiencia del pueblo Kuna, (siglos XVI-XXI), Quito, Abya-Yala, 2011.

Mena García, Carmen, Pedrarias Dávila, Sevilla, Servicio de Publicaciones de la Universidad de Sevilla, 1992.

Mira Caballos, Esteban, «La Armada Guardacostas de Andalucía y la defensa del Atlántico (1521-1550)», Revista de Historia Naval, 56, Madrid, 1997, 7-20. 
Ojeda Pérez, Robert, «Producción, comercio y contrabando del vino en el Virreinato de la Nueva Granada en el periodo colonial», Memorias, 7, Barranquilla, 2007, 93- 113.

Oliveros de Castro, María Teresa, «La Guajira y las ordenaciones de Antonio de Arévalo», Revista de Historia Militar, 39, Madrid, 1970, 92-100.

Pezuela, Jacobo de la, Sitio y rendición de La Habana en 1762. Fragmento de la Historia Inédita de la Isla de Cuba, Madrid, Imprenta de M. Rivadeneyra, 1859.

Pocock, Tom, Battle for Empire: The very first World War, 1756-1763, London, Caxton Publishing, 2002.

Robles, Gregorio y Tau, Víctor, América a fines del siglo XVII: noticias de los lugares de contrabando, Valladolid, Publicaciones Universitarias, 1980.

Rodríguez, Nelson Eduardo, «El imperio contraataca: las expediciones militares de Antonio Caballero y Góngora al Darién», Historia crítica, 53, Bogotá, 2014, 201-223.

Romoli, Kathleen, Los de la lengua cueva. Las tribus del istmo oriental al tiempo de la conquista española, Bogotá, ICAN, 1987.

Sáenz de Santamaría, Carmelo, «Inglaterra y el Reino de Goathemala. Influjo inglés en dos economistas guatemaltecos del periodo hispano, escasamente conocidos», Revista de Indias, XLII, 167-168, Madrid, 1982, 109-201.

Santa Teresa, Severino, Historia documentada de la iglesia de Urabá y el Darién. Desde el descubrimiento hasta nuestros días, Bogotá, Ed. Kelly, 1956.

Vásquez Pino, Daniela, «Políticas borbónicas en la frontera. El caso del Darién. 1760- 1810», Revista Historia 2.0, II-3, Bucaramanga, 2012, 89-103.

Vaughan, Edgar, «La colonia escocesa en el Darién (1698-1700) y su importancia en los anales británicos», Boletín Cultural y Bibliográfico, IX-2, Bogotá, 1966, 189-218.

Vargas Sarmiento, Patricia, Los embera y los cuna: impacto y reacción ante la ocupación española. Siglos XVI y XVII, Bogotá, Instituto Colombiano de Antropología, 1993.

Wafer, Lionel, Los viajes de Lionel Wafer al istmo del Darién. (Cuatro meses entre los indios) [1705], traducidos y anotados por Vicente Restrepo, Medellín, Colección Biblioteca Popular de Urabá, 1990.

Zapatero, Juan Manuel, «Expediciones españolas al Darién. La del ingeniero militar don Antonio de Arévalo en 1761», Revista Historia Militar, 19, Madrid, 1965, 49-79. 